B.P. Singh et.al

\title{
FREE ENERGY OF MIXING AND ACTIVITY OF HgK LIQUID ALLOY
}

\author{
B.P. Singh ${ }^{1}$, I.S. Jha ${ }^{2}$ and D. Adhikari ${ }^{2}$ \\ ${ }^{1}$ University Department of Physics, T.M. Bhagalpur University, India \\ ${ }^{2}$ M.M.A.M. Campus, Biratnagar, Tribhuvan University, Nepal
}

\begin{abstract}
The large asymmetry observed in free energy of mixing of $\mathrm{HgK}$ liquid alloy is discussed on basis of Flory's model. The concentration dependence of the free energy of mixing and activity of mercury has got special attention in the discussion.
\end{abstract}

Key words: liquid alloy, Flory's model, Free energy of mixing, activity.

\section{Introduction}

The free energy of mixing and activity of $\mathrm{HgK}$ liquid alloy show large deviation from the ideal values [1,5]. The observed values of free energy of mixing $\left(\mathrm{G}_{\mathrm{M}}\right)$ are quite asymmetrical around the equi-atomic composition $(\mathrm{c}=0.5)$ and they show large minima near $60 \%$ of $\mathrm{Hg}$ [1].

In the present work, Flory's expression for the free energy of mixing has been used to explain the alloying behavour of $\mathrm{HgK}$ liquid alloys.

Working expressions and the results for free energy of mixing and activity are given in Section 2 and 3 receptively. Conclusion of the work is given in section 4 .

\section{General Formalism}

Flory's expression for the free energy of mixing of a binary mixture consisting of Nc mole of species $\mathrm{A}(=\mathrm{Hg})$ and $\mathrm{N}(1-\mathrm{c})$ mole of species $\mathrm{B}(=\mathrm{K})$ is given by [2].

$$
\mathrm{G}_{\mathrm{M}}=\mathrm{RT}[\mathrm{c} \ln \mathrm{c}+(1-\mathrm{c}) \operatorname{In}(1-\mathrm{c})+\mathrm{c} \ln (1-\beta)-\operatorname{In}(1-\beta \mathrm{c})]+\omega \mathrm{c} \frac{1-\mathrm{c}}{1-\beta \mathrm{c}},
$$

where $\beta=1-\frac{\mathrm{V}_{\mathrm{A}}^{0}}{\mathrm{~V}_{\mathrm{B}}}$

$\mathrm{V}_{\mathrm{A}}^{0}$ and $\mathrm{V}_{\mathrm{B}}{ }^{0}$ being the atomic volumes of species $\mathrm{A}$ and $\mathrm{B}$ respectively $\left[\mathrm{V}_{\mathrm{B}}{ }^{0} / \mathrm{V}_{\mathrm{A}}{ }^{0}=3.3\right.$ at $600 \mathrm{~K}$. (Simoji 1977) $]$. [4]

Activity is a very important thermodynamic function because it is one of the fortunate functions which are obtained directly from experiment. The activity (a) of an element in a binary liquid is given by

Where

$$
\mathrm{K}_{\mathrm{B}} \mathrm{T} \text { Ina }=-\mathrm{ZFE}
$$

$\mathrm{Z}=$ valency of carrier ions of the element

$\mathrm{F}=$ Faraday's constant

$\mathrm{K}_{\mathrm{B}}=$ Boltzmann constant

$\mathrm{E}=$ Electromotive force which is observed directly from the experiment

In order to obtain the expression for ' $a$ ' let us recall the standard thermodynamic relation: 
BIBECHANA

Vol. 6, March 2010

$$
\text { RT In } \mathrm{a}=\mathrm{G}_{\mathrm{M}}+(1-\mathrm{c}) \frac{\partial \mathrm{G}_{\mathrm{M}}}{\partial \mathrm{c}} .
$$

Differentiating equation (i) partially with respect to 'c'

$$
\frac{\partial \mathrm{G}_{\mathrm{M}}}{\partial \mathrm{c}}=\mathrm{RT}\left[\operatorname{In} \mathrm{c}-\ln (1-\mathrm{c})+\operatorname{In}(1-\beta)+\frac{\beta}{\beta \mathrm{c}}\right]+\omega\left[\frac{1-2 \mathrm{c}}{1-\beta \mathrm{c}}+\frac{\beta(1-\mathrm{c}) \mathrm{c}}{(1-\beta \mathrm{c})^{2}}\right]
$$

Using equations (i) and (iii) in equation (ii), we get

$$
\operatorname{In} a=\ln \frac{\mathrm{c}(1-\beta)}{1-\beta c}+\frac{\beta(1-\mathrm{c})}{1-\beta \mathrm{c}}+\frac{\omega}{\mathrm{RT}} \frac{(1-\mathrm{c})^{2}}{(1-\beta \mathrm{c})^{2}}
$$

\section{Result and Discussion}

The value of interchange energy is determined form the observed data of $G_{M}$ in the concentration range from 0.1 to 0.9 [1]. The value of $\omega / \mathrm{RT}_{\text {used }}$ in the present work is -5.51 . The computed values of $\mathrm{G}_{\mathrm{M}} / \mathrm{RT}$ from equation (i) are furnished in Table -1 and plotted in Fig. -1 with its observed values at $600 \mathrm{~K}$. as a function of $\mathrm{c}_{\mathrm{Hg}}$. The computed and observed values of the free energy of mixing are in well agreement. It may be noted that the free energy of mixing of $\mathrm{HgK}$ liquid alloys exhibits asymmetry around equi-atomic composition. Our computed values of $\mathrm{G}_{\mathrm{M}}$ do not differ from the experimental values by more than $7.6 \%$ at any concentration.

Equation (iv) has been used to compute In $\mathrm{a}_{\mathrm{Hg}}$, which is tabulated in Table-2 and plotted in Fig.-2 along with the experimental values of $\ln \mathrm{a}_{\mathrm{Hg}}$ at $600 \mathrm{~K}$, [3]. The computed and observed values of activity are in reasonable agreement/ it is observed that the activity of $\mathrm{Hg}$ in the $\mathrm{HgK}$ liquid alloys remains quite a small value for most of the concentrations i.e. ${ }^{\mathrm{Hg}_{\mathrm{gg}}} \leq 0.7$ and then it rises very fast. There is slightly disagreement between the theoretical and experimental values of $\ln a_{\mathrm{Hg}}$ for small concentrations of mercury but this disagreement reduces considerably at the Hg-rich end.

\section{Conclusion}

Flory's, model has been considered to study the concentration dependence of free energy of mixing and activity of $\mathrm{HgK}$ liquid alloy. Our theoretical investigation explains the asymmetry in the free energy of mixing to a great extent. The activity has been successfully explained.

\section{References}

1. T.E Faber, Introduction to the theory of Liquid Metals, Cambridge University Pres, U.K. (1972).

2. $\quad$ P.J. Flory, J. Chem. Phys. 10, (1942) 51.

3. R. Hultgren, O.D Desai,, D.T. Hawkins, M. Gleiser, and K.K., Kelley, Selected Values of the Thermodynamics Properties of Binary Alloys, A.S.M., U.S.A. (1973).

4. M. Simoji, Liquid Metals, London Acad., U.K. (1977).

5. $\quad$ R.N. Singh, and A.B. Bhatia, J. Phys., F14, (1984) 2309. 
B.P. Singh et. al

\section{TABLES \& GRAPHS}

Table -1

Free energy of mixing of $\mathrm{HgK}$ liquid at $600 \mathrm{~K}$

\begin{tabular}{|l|l|l|}
\hline \multirow{2}{*}{$\mathrm{c}_{\mathrm{Hg}}$} & $\mathrm{GM} / \mathrm{RT}$ & \\
\cline { 2 - 3 } & Theoretical & Experimental* \\
\hline 0.1 & -0.9053 & -0.8181 \\
\hline 0.2 & -1.6135 & -1.4835 \\
\hline 0.3 & -2.1975 & -2.0927 \\
\hline 0.4 & -2.6573 & -2.6491 \\
\hline 0.5 & -2.9759 & -3.0963 \\
\hline 0.6 & -3.1206 & -3.3464 \\
\hline 0.7 & -3.0368 & -3.2809 \\
\hline 0.8 & -2.6327 & -2.7800 \\
\hline 0.9 & -1.7432 & -1.7218 \\
\hline
\end{tabular}

- Hultgen et al, 1973

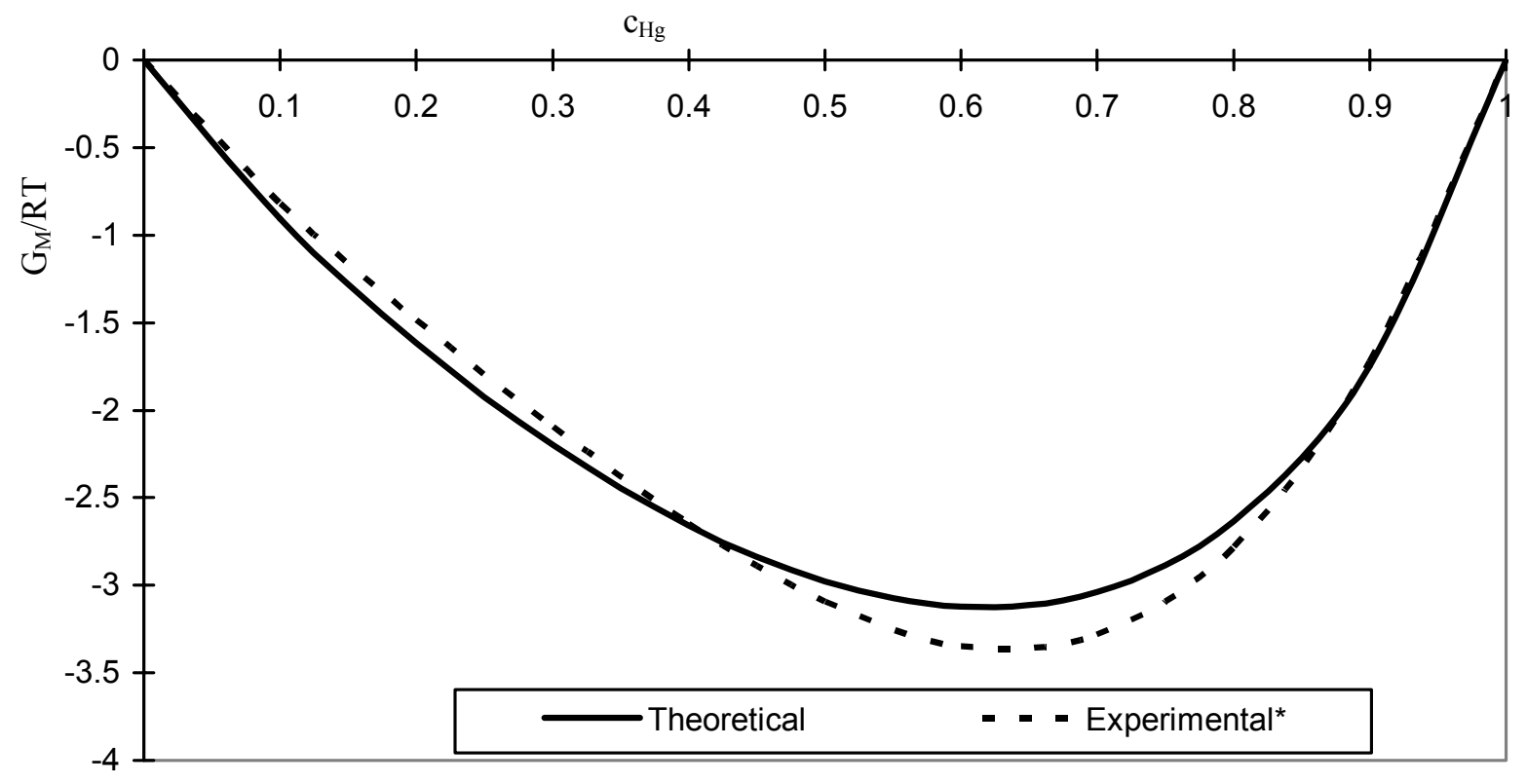

Fig.-1. $\mathrm{G}_{\mathrm{M}} / \mathrm{RT}-\mathrm{c}_{\mathrm{Hg}}$ curve for $\mathrm{HgK}$ liquid alloy at $600 \mathrm{~K}$ 


\section{BIBECHANA}

Vol. 6, March 2010

Table -2

Activity of $\mathrm{Hg}$ in liquid alloys at $600 \mathrm{~K}$

\begin{tabular}{|l|l|l|}
\hline \multirow{2}{*}{$\mathrm{c}_{\mathrm{Hg}}$} & In $\mathrm{a}_{\mathrm{Hg}}$ & \\
\cline { 2 - 3 } & Theoretical & Experimental* \\
\hline 0.1 & -7.9069 & -6.9078 \\
\hline 0.2 & -6.7666 & -6.9078 \\
\hline 0.3 & -5.8626 & -6.2146 \\
\hline 0.4 & -5.0171 & -5.8091 \\
\hline 0.5 & -4.1689 & -4.9618 \\
\hline 0.6 & -3.2883 & -3.8167 \\
\hline 0.7 & -2.3639 & -2.4889 \\
\hline 0.8 & -1.4125 & -1.2483 \\
\hline 0.9 & -0.5220 & -0.3538 \\
\hline
\end{tabular}

*Hultgren et al, 1973

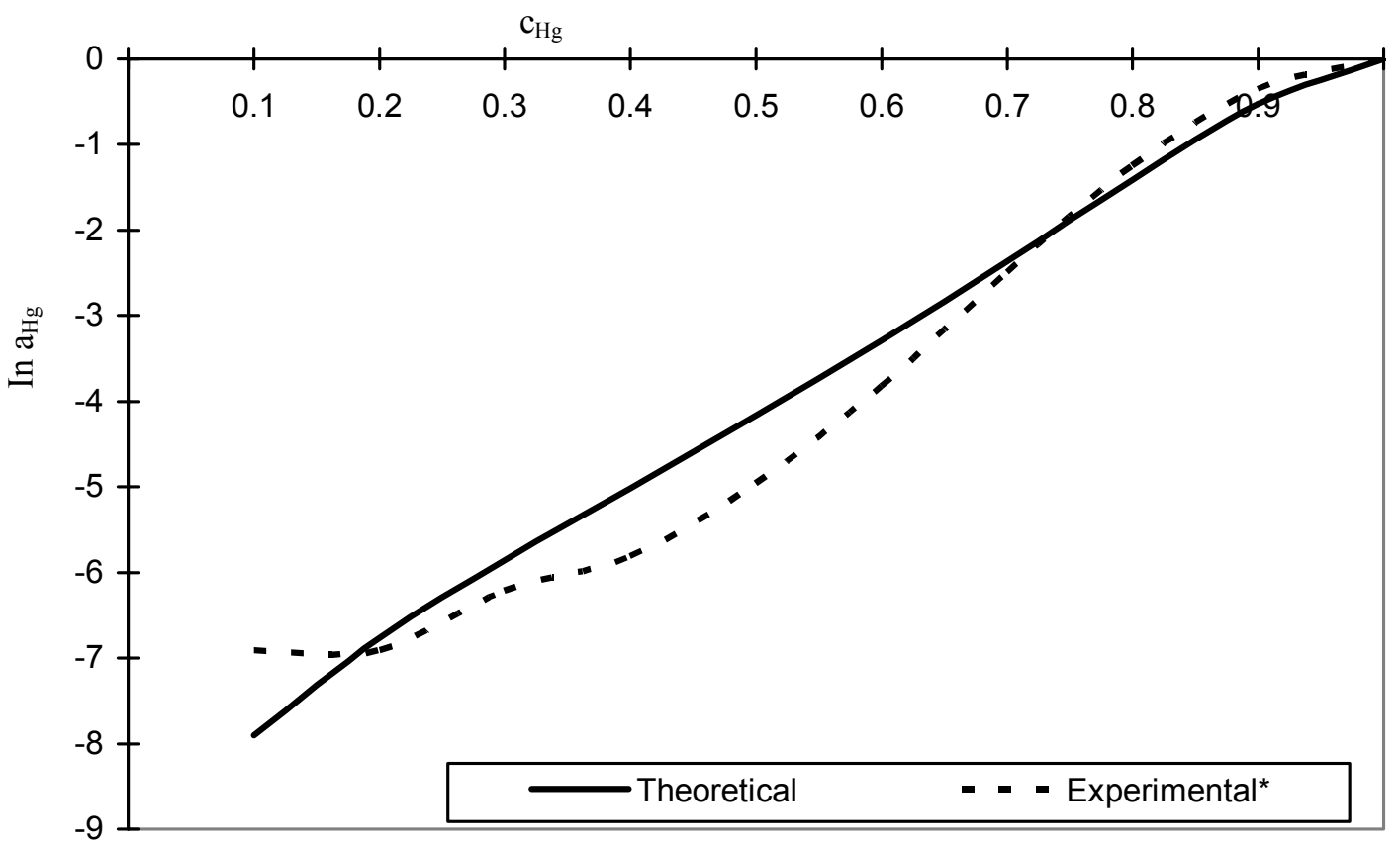

Fig.-2. In $\mathrm{a}_{\mathrm{Hg}}-\mathrm{c}_{\mathrm{Hg}}$ curve for liquid alloy at $600 \mathrm{~K}$. 